\title{
HUMAN FACTOR POSITION IN RISE AND DEMONSTRATION OF ACCIDENTS
}

This article deals with the human being - the human factor and its participation in the rise of industrial disasters (hazard - human error), in preventing their rise (hero - intrepid recoveries) and the way how the accidents affect the people in the form of impacts (victim - accident impact). It is necessary to emphasize also another role of the human factor in the rise of accidents - the solver who takes a share in coping with and managing the disaster, the so called crisis manager who will not be the object of this article. A common feature of all three groups is the psyche of the human factor (personality) and the specific is represented by the different going through and behaving of people during the rise and the course of the accident.

Key words: human factor, crisis event, accident, hero, error, victim

\section{Introduction}

\subsection{Key terms resolution}

At the beginning it is necessary to define chosen terms which will be used in the article due to the terminological heterogeneity in other sources. There are the following key terms - personality, human factor and accident that we understand as follows:

Personality is defined as an organic unity of the physical and mental, inborn and acquired properties typical for the given individual and reflecting in his/her perception, behavior and performance.

Human factor is understood as a set of human properties and abilities which in the given situation affect the performance efficiency, effectiveness and reliability of the system in various ways. It is an interdisciplinary term integrating the knowledge from biology, sociology, psychology and natural sciences which orient on achieving an optimal compliance between the people and environment (especially the working one) with the aim to minimize the number and extent of the human errors and their consequent influences. $[3,8]$

Accident (disaster) is understood as an emergency which causes a deviation from the stable operational status and results in leaking hazardous substances or performing other negative factors which affect life, health or property.

Methods utilised in the social sciences have been used in the article. Based on deduction individual definitions of the introduced area were stated and they were based on the already existing defi- nitions and their analysis and comparison with the basic assumptions in the area of industrial accident prevention. Furthermore there were general theoretical methods - analysis and synthesis through which we analysed several approaches in the Slovak Republic and abroad concerning the human factor and especially its positions in the rise and demonstration of accidents.

\section{Human contribution to accident occurrence and influence of accident on human factor}

\section{1 Human errors and recoveries in practice}

The risks connected with the technical and technological processes can be a source of unplanned interruption of the manufacturing processes or can violate providing a service and can cause material losses, damage the environment, threaten the health and lives of people. They can endanger not only the participating employees but also inhabitants from the surroundings and in the case of a leakage of dangerous substances it can become the source of violating the nature, the environment and endangering the inhabitants for a long-time period, if not forever. One of the causes of the rise of industrial accidents is also the failing of the human factor and this is one of the topics of the paper submitted.

In the past models of accidents dealing with the causes and relationships of accident rise were created. They insubstantially emphasized the human factor; it was only introduced as an immediate cause of events leading to an accident. Currently there is an effort to understand why and when the human factor affects the rise and development of serious accidents (it is the cause or part of accidents). What makes it possible to forecast, to prevent acci-

\footnotetext{
* Katarina Zanicka Holla, Valeria Moricova

Department of Crisis Management, Faculty of Special Engineering, University of Zilina, Slovakia, E-mail: katarina.holla@fsi.uniza.sk
} 
dents as well as to decrease the share of the human factor on the rise and development of serious disasters? [4]

The analysis of events which occurred and were caused by the human factor is one of the methods for creating the preventive measures. According to this method it is possible to foresee partially the human behavior in the crisis situations.

Over the past 50 years there has been a dramatic widening of the scope of accidents investigation across many different hazardous domains:

- system and cultural issues (1960s Metal fatigue, Aberfan Inbrox) - unsafe acts (errors and violations) (1970s Flixbourgh, Seveso, Tenerife TMI MT Erebus)

- equipment failures (hardware - software) (1980s Chernobyl Zeebrugge Bhopal PiperAlpha Dryden, 1990s Paddington Long Island Alabama Eschede, 2000s Linate Uberlingen Columbia). [11]

Chemical incident statistics are very sketchy with respect to root causes and many reported incidents do not furnish much detail about the cause. Chemical safety and hazard investigation board published in $600 \mathrm{~K}$ Report that:

- Among cases where the cause was known, $49 \%$ were as a result of mechanical factors, $39 \%$ from human factors and just $2 \%$ to weather-related phenomena, $10 \%$ causes not found,

- Among cases involving mechanical factors, an overwhelming $97 \%$ were attributed to general equipment failure; $63 \%$ of human factors cases were attributed to human error. [5]

The high rate of general equipment failure among reported incidents suggests that mechanical integrity/maintenance issues are significant and from the human error that training and proper procedures should also be examined.

We can introduce instances of accidents which were caused by failing the human factor or saving lives by human factor. The first of them is the Chernobyl disaster. An industrial accident of exceptional size had a lot of victims that cannot be counted exactly (the epidemiological analysis is not available). Various scientific studies assume from 9,000 to 475,000 victims. The most frequent conclusions and maybe the most probable values are in several tens of thousands $(30,000$ to 60,000$)$. The 1986 Summary Report on the Post-Accident Review Meeting on the Chernobyl Accident (INSAG-1) of the International Atomic Energy Agency's (IAEA's) International Nuclear Safety Advisory Group accepted the view of the Soviet experts that "the accident was caused by a remarkable range of human errors and violations of operating rules in combination with specific reactor features which compounded and amplified the effects of the errors and led to the reactivity excursion." In particular, according to the INSAG-1 report: "The operators deliberately and in violation of rules withdrew most control and safety rods from the core and switched off some important safety systems."

Another example of the human factor failure in the environment of the nuclear power stations is the disaster Three miles island which happened at 4 am on $28^{\text {th }}$ March 1979 and where the second nuclear reactor was partially melted. The operational building was contaminated and an extensive leakage of radioactivity to the environment also occurred. The investigation commission later designated for the reason of the accident a breakdown of the safety valve. The proportion of the human factor was that operators were unable to diagnose or respond properly to the unplanned automatic shutdown of the reactor. Deficient control room instrumentation and inadequate emergency response training proved to be root causes of the accident.

Last example is connected to another type of accident - nearly accident. As an example we can introduce the Apollo 13 program. Its objective was the third landing of the human crew on the Moon surface, this time in the area of Fra Mauro. The typical sentence: "Houston, we've had a problem," says how very close the crew was to a disaster. During the flight one of the oxygen tanks exploded and seriously damaged the service module. The consequences of this explosion were serious. Not only this situation caused the crew did not fulfill the task of this flight but it threatened the lives of the crew members. The Manned Spacecraft Centre (today Lyndon B. Johnson Centre) had to develop with an extreme effort emergency scenarios thanks to which they succeeded in transporting the crew alive back to the Earth. Hundred of people were involved in the rescue: off - duty controllers, astronauts, simulation technicians, contractors' personnel and many more. But this case is only to show how the team effort, and a magnificent display or sheer unadulterated professionalism, both in he spacecraft and on the ground brought the crew to the Earth alive. [11]

All crisis events have a potential impact on human factor as it was showed in previous text. We can mention human death, injuries, homeless people and other negative impact. Another type of negative impact on personality psyche relate to the human perception and behavior.

\subsection{Human factor positions in case of accident occurrence}

There is a stark contrast between unsafe acts and these intrepid recoveries. Errors and violations are commonplace, banal ever, they are as much as a part of human condition as other ordinary human activities. Successful recoveries, on the other hand, are singular and remarkable events.

The human factor in relation to the rise and demonstrations of the industrial accidents can play several roles. These roles are as follows:

- the human factor as the cause of the rise of the industrial accidents (hazard - human error),

- the human factor as the recipient of the negative consequences of the industrial accidents (victim - negative impact),

- the human factor as a hero (hero - heroic recoveries). 
Human Factor as the Cause of the Rise of Industrial Accidents

When the human factor fails, there is a whole chain of small errors which if occurred individually they would not have fatal consequences. However, from a certain point on the tragedy is unavoidable.

There are several definitions of the human error. One of them says that the error is an action or a decision which was not determined (planned) and which leads to undesirable result. [13] Furthermore, the human error defines a certain fact, statement or decision which deviates from the standard and the result is an actual or potential unfavorable event. However, this event can but also need not lead to an unfavorable result.

There are several possible definitions and there are also many ways in which errors can be classified. When we are talking about deviations concerning the human error we should mention such deviations that could be from upright (trip or stumble), from the current intention (slip or lapse), from an appropriate route towards some goal (mistake), or in some circles, it could even involve straying from the path of righteousness ( $\sin )$.Human error classification should be done based on possible generic classification based on action: omission, intrusions, repetitions, wrong objects, disordering, mistiming, blends etc.

In the industrial processes there are the following possible causes of errors and failure of the human factor: bad reflection of risks of the attendants; errors in communications; insufficient or incorrect knowledgeability of the employees, insufficient qualification, insufficient experience (lack of training) - practice, personality and health assumptions of the employees; failing to keep the working procedure; unsuitable working conditions and working environment; inattentiveness (momentary) of the employees and many others. $[7,8]$

\section{Human Factor as Hero (Intrepid Recoveries)}

Another perspective according to human factor, one that has been relatively little studied in its own right is human factor as a hero. This presents a human factor as an element whose adaptation and compensation have brought trouble systems back from the brink of disaster on a significant number of occasions. We have already presented an example Apollo 13 where human factor saved several lives of astronauts. Other examples to be mentioned concerned to intrepid recoveries are connected to aeroplane crashes for example British airways flight 09 from London Heathrow to Aucland then BAC 1 - 11 flight to Malaga and many others.

Reason (2010) presents: "I find the heroic recoveries of much greater interest and in the long run, potentially more beneficial to the pursuit of improved safety in dangerous situations (operations)."

\section{Human Factor as Recipient of Negative Consequences of Industrial Disasters}

As already mentioned people are in many cases the reason for rising industrial accidents and they also significantly affect their development. However, on the other hand, people are also affected by them, tangibly by their negative consequences. The accidents affect the people - their lives, health, property but also the environment in dependence on the concrete form of the accident. The impacts on people can be divided into two groups, namely the impacts on the employees working in the company and impacts on the non-employees (the general public). The impacts of the industrial disasters on the employees according to their levels can be: death of the employee; serious damage of health with permanent consequences; serious industrial accident; light industrial accident; dangerous event (almost an accident); stress resulting from the situation arisen

\subsection{Psyche of Human Factor in the Rise and Performance of Accident}

The survival of the human being in all roles is a common denominator. The disasters have an impact on the whole human personality; they affect people's survival which subsequently reflects also in their behavior (see Fig. 1). The accuracy of the psychical processes decreases: the sense cognition (feeling, perceiving), intellectual recognition (e.g.: of the way of thinking, attention, memory) that can lead to the rise of further errors which can cause further accidents. They also affect the overall life of a human being. The human psychics play an important role also from the point of view of industrial accidents (human error) and intrepid recoveries (human as a hero). On Fig. 1 there are shown psyche parts. It consists of consciousness, unconsciousness and perception. The psyche appears in human behavior also externally which has connection with behaving human factor in rise and demonstration of technological accidents too.

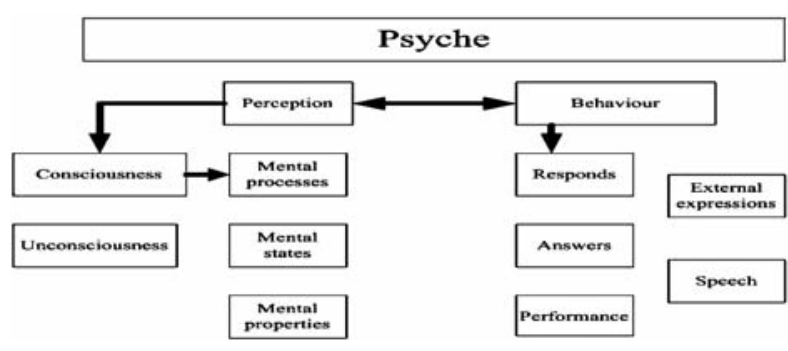

Fig. 1 Personality psyche structure

Personality psyche has very wide possibilities of use in this area and also offers many ways of research possibilities. This should be an idea to develop for another article.

\section{Conclusion}

The aim of this article was to assess and specify the position of the human factor from the point of view of the rise and performing the consequences of the crisis phenomena. It is necessary to emphasize that each of these roles has its specifics in which the 
psyche of the people plays an important role. Especially the role of the human factor as a hero seems interesting due to the fact that it is one of the potential preventive tools when preventing the industrial accident. The individual roles of the human factor during the rise and development of the accident can be played by one person who can cause the accident as well as to solve it; however, each role can be played by an individual person. The analysis of the causes of the rise of the industrial accidents, the intrepid recoveries and the ways of the human perception in the case of demonstration of industrial accidents provides an incredible space for research activities and opens new horizons of knowledge.The area of the human factor is a key one in the crisis management and new facts should be incorporated in the study material of Faculty of Special Engineeringof University of Zilina also in a form of a special subject. Similarly the research results have opened a space for a further investigation aimed especially at the research of specifics of survival and behaviour of the human factor (personality) in three positions identified.

Preparation of this paper has been supported by Institutional project: Human Factor in Crisis Management

\section{References}

[1] BELL, J., HOLROYD, J.: Review of Human Reliability Assessment Methods, [on line], Norwich : First published, 2009. [cit. 201011-2]. Available on: http://www.hse.gov.uk/research/rrpdf/rr679.pdf , 2009.

[2] BERRY, L. M. 2009. Psychology at Work, Bratislava : Ikar, 2009, p. 693, ISBN 978-80-551-1842-0

[3] DZVONIK, O., KRIZ, J., BLASKO, P.: Human Factor in Flying. Human Effectiveness and Its Limits, Zilina : EDIS - ZU, 2001. p. 148, ISBN 80-7100-811-7

[4] FEYER, A. M., WILliAMSON, A. M. 2010. Human Factors in Accident Modelling. [on line]. 2010. [cit. 2010-11-13]. Available on: http://www.ilo.org/safework_bookshelf/english?content\&nd=857170643, 2001.

[5] GARCIA, D.: The Debate About Chemical Accidents: Where Do We Stand? [on line]. [cit. 2010-11-12]. Available on: http://www.acusafe.com/Newsletter/Stories/ 0800News-ChemicalAccidentsDebate.htm, 2002.

[6] LOVECEK, T.: Present and Future Ways of Physical Property Protection, In: Communications - Scientific Letters of The University of Zilina, 2008. ISSN 1335-4205, p. 35-39.

[7] MALY, S.: Human Factor in Safety Documentation According to Act No. 353/1999 Sb. About Major Accidents Prevention. [on line]. VUBP Prague, 2002. [cit. 2010-11-10]. Available on: http://www.bozpinfo.cz/utf/knihovna-bozp/citarna/clanky/lidsky_cinitel/ lc020308.html, 2002.

[8] Methodical directive of environmental risk of Ministry of Environment of Czech Republic for documents creating „Principles, goals and policy of major accidents prevention" and "System description of safety management" according to act. no 59/2006 about major accident prevention, Bulletin of Ministry of Interior, 2006, No. XVI., part 12.

[9] MIKA, V., SIMAK, L., HUDAKOVA, M., HORACEK, J.: Management and Crisis Management, Zilina : EDIS - ZU, p. 204, ISBN 978-80-554-0079-2, 2009.

[10] PROVAZNIK, V. et al.: Psychology for Economists and Managers, Prague : Grada Publishing, 2002, p. 228, ISBN 80-247-0470-6, 2002.

[11] REASON, J.: The Human Contribution, Burlington, MPG Books Ltd., p. 295, ISBN 978-0-7546-7402-3, 2002.

[12] REASON, J.: Human Error, Cambridge : Cambridge University Press, p. 291, ISBN 978-0-521-31419-0, 1990.

[13] Strategy for Handling Human Error, [on line]. 2010. [cit. 2010-11-20]. Available on: http://www.sikkerhetsdagene.no/ Tidligere\%20konferanser/2007/balfour.pdf, 2006.

[14] ZANICKA HOLLA, K., RISTVEJ, J., SIMAK, L.: Risk Assessment in Industrial Processes, Bratislava : Iura Edition, s. r. o., 2010, p. 155, ISBN 978-80-8078-344-0, 2010. 